\title{
HEGEL POETA. HUYENDO DE LAS FUGAS
}

\author{
HEGEL AS A POET. ESCAPING FROM ESCAPES
}

\section{Valerio ROCCO LOZANO}

Universidad Autónoma de Madrid

Resumen: El presente artículo analiza las principales temáticas y algunos aspectos estilísticos de la producción poética de Hegel, comprendida entre los años 1796 y 1800. No sólo Eleusis, su poesía más conocida, sino todas las composiciones poéticas de Hegel tratan el tema de la posibilidad de una reconciliación entre la naturaleza y el espíritu, superando las dicotomías de la filosofía kantiana. La influencia de Hölderlin y la posibilidad de una fuga hacia lo irracional son los motivos principales que inducen a Hegel a escribir en verso. Estos dos factores son, asimismo, las principales causas del posterior abandono de la poesía por parte del autor de la Fenomenología del Espíritu.

Palabras clave: idealismo, romanticismo, Hegel, Hölderlin, poesía, intuición, Eleusis, perro.

Abstract: The present article analyses the main topics and some stylistic aspects of Hegel's poetic production, from 1796 to 1800 . Not only Eleusis, his best known poem, but all Hegel's poetic compositions deal with the possibility of a reconciliation between nature and spirit, overcoming the dichotomies of Kantian philosophy. Hölderlin's influence and the possibility of an escape into the irrational are the main reasons that induce Hegel to write in verse. These two factors are also the main reasons for the subsequent abandonment of poetry by the author of the Phenomenology of the Spirit.

Key words: Idealism, Romanticism, Hegel, Hölderlin, poetry, intuition, Eleusis, dog. 
a producción poética de Hegel es escasa en cuanto a su volumen y además muy concentrada por lo que respecta a su extensión temporal. En efecto, tal y como ya sostuvo Rosenkranz (1844, pp. 83-85), se reduce a tres poemas y tres fragmentos de poema, escritos entre 1796 y 1800, y correspondientes por tanto al final de la época de Berna y la época de Frankfurt. Ninguno de ellos fue publicado y la mayor parte quedó en una fase de esbozo. Por su extensión, su calidad literaria y su grado de ejecución sobresale entre todos Eleusis, dedicado a Hölderlin y fechado en agosto de 1796 ${ }^{1}$. Entre diciembre de 1798 y 1800 Hegel escribió otros dos poemas: "Poema a su perro", fechado en agosto de 1798; y "De un poema a la naturaleza", que lleva la fecha de 12 de diciembre de 1798. También se han conservado tres borradores: uno de ellos (que comienza con el verso "Contra las olas incesantes del torrente") está precisamente fechado, el 21 de agosto de 1800. Un segundo fragmento, que empieza por el verso “¡La primavera amenaza! Urge a la vida ahí fuera”, está escrito en algún momento sin precisar del año 1800, al igual que el último esbozo, un poema ceremonial a las princesas de Hessen-Homburg ${ }^{2}$.

El tema general de la mayor parte de estos poemas y fragmentos es la contraposición entre la naturaleza y el espíritu, así como el ensayo de diferentes modos de reconciliación entre estas dos esferas, que habían quedado radicalmente escindidas en el dualismo kantiano. La mayoría de estas posibilidades de síntesis se volverán pronto insuficientes - o incluso inaceptables - para el propio Hegel, que renegará de muchas de las concepciones filosóficas expresadas en sus poemas. Es posible que, también por ello, el filósofo limitara su producción poética a este corto período y no volviera, en los 31 años de su vida posteriores a 1800, a cultivar el género. Esto, al menos, es lo que parece indicar el rastro documental. También la influencia de Hölderlin, el gran amigo y referente de estos años, una clave decisiva del contenido y de la forma poética de estos escritos de Hegel, pronto se volverá para él — tras su caída en la locura a partir de 1801 - un doloroso recuerdo.

La decisión de Hegel de escribir poemas — una mezcla de elementos filosóficos, formales y biográficos - se debió a los mismos factores que le condujeron a abandonar la poesía o, más propiamente, a querer escapar a lo largo de toda su vida de esa producción poética suya. En este sentido, pude decirse sin exageración que toda la obra madura de Hegel puede explicarse como una fuga de Eleusis. Esta es la tesis de Kelly en su libro, publicado en 1978, titulado bien significativamente

\footnotetext{
${ }^{1}$ Recogido en español en la edición (Hegel, 2014b, pp. 285-287), preparada por José María Ripalda y titulada El joven Hegel. Ensayos y esbozos. Esta edición, publicada contemporánea e independientemente al volumen 2 de Gesammelte Werke en la editorial Felix Meiner (Hegel, 2014a), sigue su propio criterio editorial; al menos en el caso de los poemas, resulta, por varias razones, incluso preferible a la propia edición crítica alemana. En la edición crítica el poema Eleusis se encuentra en el tomo I, concretamente en (Hegel, 1989, pp. 399-402).

${ }^{2}$ Estos poemas se encuentran en la edición crítica (Hegel, 2014a, pp. 609-611), a excepción del último, que está en (Hegel, 2014a, pp. 393-396). En español están recogidos por Ripalda en (Hegel, 2014b, pp. 486-488), a excepción del último, que se encuentra en el apéndice de la mencionada edición: (Hegel, 2014b, pp. 502-504).
} 
Hegel's Retreat from Eleusis ${ }^{3}$. El titánico sistema hegeliano, impresionante por su ambición y coherencia, en el que acontece la "consumación" de la filosofía ${ }^{4}$, podría explicarse en su totalidad, según este estudioso americano, como una retirada, como un deseo del autor de la Fenomenología de huir de un pequeño poema de dos páginas, publicado por Rosenkranz trece años después de la muerte de su autor. Esta desproporción aparente entre una causa tan nimia y su presunto, gigantesco efecto, debe ponernos en guardia ante estos versos cien veces interpretados, mil veces comentados por los Hegel-Kenner de todo tipo y condición. ¿Qué misterio encierra esta poesía dedicada a la inefabilidad de los misterios eleusinos? El libro de Kelly no responde a esta cuestión. No la afronta. De hecho, apenas habla de Eleusis. Pero tan sólo con su título, nos abre a la sospecha de que la presencia latente de este poema juvenil corroe, como una infección nunca curada del todo, las sólidas y grandes obras hegelianas de madurez.

Si el sistema de Hegel es en verdad una fuga de Eleusis, entonces es la fuga de una fuga. De hecho, el poema ya de por sí puede considerarse una huida, en muchos sentidos. En primer lugar, desde el punto de vista biográfico, es el documento que da fe de una voluntad y una esperanza de huir, de cambiar de vida y de condición. De hecho, como subrayan unánimemente todos los intérpretes, la poesía fue escrita para celebrar la noticia de que por fin, en agosto de 1796, Hegel tenía la posibilidad de abandonar la odiada mansión del capitán Von Steiger, en Berna, para trasladarse a Frankfurt, junto con su amigo Hölderlin, que de hecho había sido el principal responsable de que le contrataran en la preciosa mansión de los Gogel en Roßmarkte Platz, como atestiguan las cartas de la época ${ }^{5}$. La doble alegría de Hegel por abandonar la penosa vida en Suiza y por reencontrarse con su mejor amigo inspiran la escritura del poema y explican la dedicatoria, "A Hölderlin". Muchos estudiosos han argumentado que el poema fue enviado por carta al amigo, lo que explicaría algunas asombrosas coincidencias entre estos versos y los de la celebérrima elegía Pan y vino. Sin embargo, la mayoría coincide en que "Hegel, según todos los indicios, no envió el poema (que debe ser considerado como un borrador)" (Duque, 1998, pp. 354-355) ${ }^{6}$. Lo guardó para sí, probablemente como recuerdo de la perspectiva y la esperanza de días felices.

Eleusis representa pues el testimonio de esa fuga en la biografía hegeliana, un cambio de residencia con fuertes implicaciones en la mutación de su pensamiento, aunque hoy en día la crítica tienda a subrayar la continuidad entre las etapas de Berna y Frankfurt y a minimizar la importancia de

\footnotetext{
${ }^{3}$ Cfr. Kelly (1978, p. 3): "as Hegel retreated from his Romantic world of Eleusis, he discovered and clarified a world at the service of human reason".

${ }^{4}$ Cfr. Heidegger (2001, p. 345): “Con el nombre «los griegos» pensamos en el comienzo de la filosofía; con el nombre «Hegel», en su consumación. El propio Hegel entiende su filosofía de acuerdo con esta determinación”.

${ }^{5}$ Cfr. Hoffmeister (1952, p. 41): Hölderlin le anuncia a Hegel: "Vorgestern kommt Herr Gogel ganz unvermutet zu uns und sagt mir, wenn Du noch frei seist und Lust zu diesem Verhältnis hättest, würd es ihm lieb sein. Du würdest zwei gute Jungen zunächst zu tilden haben [...]". Cfr. etiam la respuesta de Hegel en la pág. 43: "In Ansehung der ökonomischen und anderer Verhältnisse ist es zwar oft der Klugheit gemä $\beta$, sich genau darüber zu erklären; ich glaube aber hier, dieser Vorsicht entbehren zu können und überlasse es Dir, mein Interesse zu besorgen [...]”.

${ }^{6}$ De la misma opinión es Harris (1972, p. 244): "The poem is addressed to Hölderlin, but I do not think this should be taken to mean that it was conceived as a letter."
} 
la diferencia de influencias que marca cada período ${ }^{7}$. Pero si entramos ya en el análisis de los versos, vemos que a la alegría por este rencuentro motivado por la huida se suma, de forma recíproca, el dolor por la lejanía de los días felices transcurridos con el amigo en el seminario de Tubinga:

Tu imagen, amado, aparece ante mí,

y el placer de los días huidos; mas pronto los apartan

las dulces esperanzas de volver a vernos $(\text { Hegel, } 1989,399)^{8}$.

Los días huidos, pasados para siempre, son tildados de felices. Y sin embargo, las narraciones de la etapa tubinguesa relatan la disconformidad de Hegel y Hölderlin, junto con el tercer compañero, cinco años más joven que ellos, Schelling, con los anticuados métodos de enseñanza ${ }^{9}$ y de evaluación ${ }^{10}$ del Stift, con el modo de vida que allí llevaban ${ }^{11}$, con el intento por parte de la "fe degenerada" de profesores como Storr de conciliar kantismo y Cristianismo, con las reacciones de las autoridades del Seminario e incluso del propio Ducado frente a la Revolución francesa (Cfr. D’Hondt, 1976, p. 71). Hasta tal punto se encontraba Hegel a disgusto en el Stift, que durante el último año apenas lo pisó, alegando problemas de salud sobre cuya autenticidad los maestros y preceptores albergaban serias dudas. Como se infiere de una carta de Hölderlin a Hegel, éste ni siquiera se planteó solicitar un puesto de Repetent en el Seminario al acabar los estudios, dado que le habría sido difícil ejercer su labor educativa de "resucitador" rodeado de tantos "enterradores" (Hoffmeister, 1952, p. 34). ¿Por qué, por lo tanto, el mismo Hegel que había escapado de ese ambiente funerario, añora algunos meses más tarde "el placer de los días huidos" de Tubinga? Puede que se trate de un tópos literario, de una mera convención para expresar su alegría por el reencuentro próximo. Sin embargo, antes de proseguir, es preciso recordar que durante su estancia en el Seminario, Hegel vivió los emocionantes acontecimientos de la Revolución francesa, y que, participando activamente en un club de tendencia girondina $^{12}$ que se formó entre los profesores y estudiantes con simpatías francófilas, soñó la

\footnotetext{
${ }^{7}$ Cfr Duque (1996b, pp. 225-226): "la estrecha afinidad de la temática desmiente claro está una demasiado tajante separación de las dos épocas: como si Hegel hubiera ido reaccionando pasiva y automáticamente a los influjos que le llegaran de una época o mentor (por caso, Kant en Berna, Hölderlin en Frankfurt)".

${ }^{8}$ En este artículo se seguirá la traducción de Félix Duque, publicada en (Duque, 1998, p. 350). La versión de la traducción de José María Ripalda se encuentra, como ya se ha indicado, en (Hegel, 2014b, pp. 285-287).

${ }^{9}$ Cfr. Pozzo (1989, pp. 54-55): "senza dilungarsi sulle numerose consuetudini affatto obsolete che ancora sopravvivevano al tempo del soggiorno di Hegel, è opportuno richiamarne almeno due, in quanto hanno diretto riferimento sul modo in cui era svolto l'insegnamento della logica: l'obbligo di parlare e di scrivere in latino e la pratica di sostenere disputationes pubbliche. Ancora nel 1725, nel momento in cui la terminologia in lingua tedesca iniziava a fissarsi grazie agli scritti in lingua tedesca di Wolff, a Tubinga si esigeva che gli studenti parlassero tra di loro in latino. Connessa alla sopravvivenza del latino era la pratica delle disputationes. [...] Anche a Hegel toccó dunque sottoporsi a stremanti esercizi disputatorî, sia in filosofia che in teologia, e diverse volte, in sede d'esame, dovette rispondere a delle tesi o difendere delle dissertazioni. Va da sé che dalla fine del XVIII secolo questo strenuo attaccamento al latino si dimostrava del tutto inutile, quando non controproducente, poiché a quel tempo il tedesco filosofico aveva raggiunto un notevole grado di precisione ed esattezza". ${ }^{10}$ Cfr. D’Hondt (2002, p. 53): “aunque entró en el seminario como el estudiante más brillante de su clase, el desinterés que pronto manifestó por sus estudios oficiales y una cierta arrogancia en sus actitudes no le ayudaron a conservar ese primer puesto cuando se realizó la primera prueba".

${ }^{11}$ Cfr. ibidem: "se les obligaba a llevar largas vestiduras negras (que se asemejaban a las sotanas), con cuellos y puños blancos [...]. La desobediencia de las reglas comportaba castigo, que usualmente consistía en la privación de vino en la mesa o en el encarcelamiento en la prisión de la institución".

${ }^{12}$ El hecho de que Hegel criticara con vehemencia, como por ejemplo en la carta a Schelling de Nochebuena de 1784, en (Hegel, 2014b, p. 79]) la "vileza de los robespierristas", y su clara afiliación a la facción girondina no debe llevarnos a
} 
exportación de estas mutaciones a su lado del Rin, dejando innumerables muestras (en sus cuadernos, en sus diarios, en los testimonios de sus compañeros) de una inquebrantable esperanza en un próximo cambio político y social también en Alemania. Los "días huidos", para quien escribe en agosto de 1796, son también los días del compromiso activo, ilusionado y sin fisuras con el proyecto revolucionario. Tras la interrupción, por parte del Directorio, de las ayudas a los revolucionarios alemanes, y sobre todo tras la experiencia del Terror y la clara muestra de ávido expansionismo belicista por parte de la joven République, Hegel podía considerar que los días de "aquel entusiasmo que la libertad infunde por todas las venas de un ser vivo" (Hegel, 2014b, p. 265), habían huido para siempre $^{13}$.

Sin embargo, es preciso señalar que este pesimismo de 1796 sobre las posibilidades de difusión europea del movimiento revolucionario francés se trocaría al año siguiente, en 1797, en todo lo contrario, en una esperanza de cumplimiento de las promesas de los dos antiguos compañeros. De hecho, con la firma del tratado de Campo Formio, con la ocupación de la ciudad de Maguncia por parte de los “jacobinos alemanes" de Georg Forster, y sobre todo con el congreso de Rastatt, al que asistió Hölderlin como acompañante de su amigo el ministro Isaak von Sinclair, se abrían nuevas perspectivas para un rápido cambio de los acontecimientos (D’Hondt. 1976, p. 124). Pero este breve repunte de entusiasmo revolucionario en los dos amigos es posterior a la redacción de Eleusis, que por lo tanto debe entenderse también como la lamentación por la pérdida de ese clima de inocente y pura exaltación que había invadido el Stift ante la noticia de los acontecimientos en Francia.

Pero esta nostalgia hacia las esperanzas de un proyecto político frustrado no es, ni mucho menos, la única fuga de la que la habla Eleusis. En los versos iniciales, Hegel se pierde en la imaginación del rencuentro con Hölderlin. Este encuentro soñado es a la vez físico, a través de un "abrazo largo tiempo anhelado y fogoso", como espiritual, es decir, la búsqueda de la

[...] dicha de la certeza

de hallar más firme y madura la lealtad a la antigua Alianza,

la Alianza, sin ningún juramento sellada

de vivir solamente por la libre verdad y nunca, nunca

hacer las paces con el dogma, que opinión y sensación cordial regula (Hegel, 1989, 400).

subrayar una presunta moderación o incuso un conservadurismo del joven Hegel. De hecho, como ha subrayado D’Hondt (2002, p. 64), "los biógrafos prefieren no recordar que los girondinos fueron revolucionarios a su manera, como también fueron regicidas, y se caracterizaron por su intervencionismo en el extranjero y por su belicismo".

${ }^{13}$ Una excelente reconstrucción de la difícil situación política de los francófilos alemanes en los meses entre mayo y diciembre de 1796 se encuentra en Bertaux (1992, pp. 96-100). Según Bertaux, la frustración por la actitud francesa en Alemania, en concreto por la falta de apoyo a los revolucionarios locales y por los saqueos de diferentes ciudades fue lo que inspiró ese tremendo pasaje del Hiperión, escrito precisamente en 1796, en el que las tropas del protagonista desobedecen las órdenes y pasan a cuchillo a los habitantes de la ciudad de Misistra, lo que provoca el conocido lamento del soldado dirigido a la amada lejana. Cfr. Hölderlin (1982, p. 158). 
Kelly ha ironizado sobre la inmadura tozudez de ese "nunca, nunca" ${ }^{14}$, que por cierto, también por su contexto, recuerda famosos versos manzonianos ${ }^{15}$. Pero el punto central de estos versos se halla en la otra palabra repetida, también casi con la pesada insistencia de un mantra o de una letanía. Sobre el significado de esa "alianza sin juramentos" han corrido auténticos ríos de tinta, sobre todo a partir de la interpretación de D’Hondt, según la cual se trataría de una encubierta referencia al Bund de la francmasonería (Cfr. D’Hondt, 1976, pp. 217 y sigs.). Frente a esta teoría, es mucho más probable que esta expresión evoque un texto fundamental en la formación del joven Hegel, el Julio César de Shakespeare, en el que Bruto se hacía portavoz de esa virtus estoica, sobria y viril sobre la que descansa la libertas republicana ${ }^{16}$. El joven Hegel había quedado profundamente impresionado por el drama shakespeariano, hasta el punto de que el primer texto que se conserva de la etapa del Gimnasio, la Unterredung zwischen Dreien, emula y revisa la letra y el espíritu de esa obra. La referencia en Eleusis a la libertad de los antiguos romanos ${ }^{17}$ casa perfectamente en el contexto de la nostalgia por los días de compromiso con la Revolución; de hecho, ésta, en múltiples elementos simbólicos, institucionales y artísticos, se había esforzado por instaurar un vínculo con la historia de la República romana, a la que consideró como modelo y precursora, como refleja la conocida frase de Saint-Just, citada por Marx: “el mundo está vacío después de los romanos; pero su memoria lo llena todavía, y aún profetiza la libertad [...] iQue los revolucionarios sean de nuevo los romanos!” (Marx, 1973, p. 139). Por cierto, es preciso notar que el joven Hegel recibió su conocimiento de la historia romana a través de la literatura latina, y no tanto en libros de historia o de derecho. En este sentido, incluso en la obra que marca el tránsito de la época de formación a la de madurez, la Fenomenología del Espíritu, puede rastrearse una "constelación conceptual Romanitas" a partir de las influencias de poetas y comediógrafos latinos, en especial de Horacio y de Terencio (Cfr. Rocco Lozano, 2019, pp. 133-152).

El recuerdo de los días huidos presente en Eleusis significa también la vuelta a esa etapa primigenia de la historia política, el mundo grecorromano, que no sólo los revolucionarios, sino también enteras generaciones de intelectuales alemanes ${ }^{18}$, habían tomado como modelo, y que Hegel

\footnotetext{
${ }^{14}$ Cfr. Kelly (1978, p. 3): "We have all known gifted young men who said 'never, never'. But the instances are rare where the repudiation of that 'never' produces such fertile and honest results".

${ }^{15}$ Cfr. Manzoni (2006, p. 125): "Sentir, riprese, e meditar: di poco / Esser contento: da la meta mai / Non torcer gli occhi: conservar la mano / Pura e la mente: de le umane cose / Tanto sperimentar, quanto ti basti / Per non curarle: non ti far mai servo: / Non far tregua coi vili: il santo Vero / Mai non tradir: né proferir mai verbo, / Che plauda al vizio, o la virtù derida". ${ }^{16}$ Cfr. Shakespeare (2006, p. 211): "No. Nada de juramento [...] ¿Qué mejor lazo que el de secretos romanos que han dado su palabra y que no la burlarán? ¿Ni qué otro juramento que el compromiso de la honradez con la honradez para realizar esto o sucumbir por ello? Juren los sacerdotes y los cobardes, y los hombres recelosos, decrépitos, corrompidos, y las almas que en sus padecimientos buscan sendas torcidas. Juren en pro de malas causas aquellos miserables que inspiran dudas a los hombres; pero no manchéis la clara virtud de nuestra empresa, ni la inquebrantable altivez de nuestros ánimos con el pensamiento de que nuestra causa o su ejecución necesitaban ser juradas; siendo así que cada gota de la sangre que cada romano lleva, y lleva noblemente, sería culpable de bastardía si él quebrantara la más leve parte de promesa alguna que hubiese hecho". Para las influencias de Shakespeare en el joven Hegel cfr. Rocco Lozano (2011, pp. 38 y sigs].

${ }^{17}$ Cfr. Ripalda (1978, p. 210): “El poema Eleusis recoge en forma definitiva la problemática hegeliana que hemos perseguido desde Stuttgart en formulaciones centradas en la subjetividad. En el fuego omnívoro de ésta se ha consumido ya el Humanismo de Stuttgart y la mesura ilustrada. Sin embargo, las evocaciones de la Roma republicana por Wieland y de los misterios eleusinos por Meiners muestran una vez más la pervivencia de topoi ilustrados en Hegel”.

${ }^{18}$ Cfr. Duque (1996a, p. 29): "Das Land, wo der Mensch nicht mehr imstande war, seine Empfindsamkeit mit seinem kalten, berechnenden Verstand auszusöhnen, und wo man deshalb einmal nach einer Lösung, nach einer Erlösung
} 
y Hölderlin elogiarán, desde múltiples puntos de vista y no sin evoluciones, en numerosos lugares de sus obras. La nostalgia de un pasado soñado puede ser mucho más fuerte que la de un pasado vivido; de hecho, la evolución filosófica de Hegel puede ser entendida en cierta manera como el esfuerzo por dejar atrás esta nostalgia, por reconocer la inviabilidad de un proyecto político basado únicamente en una fuga a lo originario, a la imitación estéril de una Antigüedad prototípica ${ }^{19}$; los dos amigos de Tubinga entenderán cada vez más su tarea en relación con el pasado grecorromano (cada vez más griego y menos romano) como comprensión de las insuficiencias de un modelo que es preciso retomar, pero perfeccionándolo y traduciéndolo a las circunstancias actuales (Cfr. Duque, 1996a, pp. 53-54).

El sueño de volver a hablar con el amigo Hölderlin de los proyectos políticos de transformación de la sociedad, así como la referencia a una Antigüedad soñada en cuanto modelo de sociedad, es lo por tanto lo que inflama la emoción de Hegel, que se deja transportar por este deseo al borde de la inconsciencia:

\footnotetext{
Ahora con la inerte realidad pacta el deseo, que ligero a través de montañas y ríos hacia ti me llevó, mas un suspiro anuncia presto de ambos la discordia, y con él huye el sueño de dulces fantasías (Hegel, 1989, p. 400).
}

La segunda huida que se narra en Eleusis es la de este sueño, que se desvanece tras una momentánea conciliación de la realidad y del deseo, del ser y del deber ser. Mutatis mutandis, y si prescindimos del diferente papel que la razón juega en las etapas de juventud y de madurez, estos cuatro versos no se distancian mucho, en cuanto a su significado, del conocido lema de los Principios de Filosofía del Derecho: "lo realmente efectivo es racional, y lo racional es realmente efectivo" (Hegel, 2005, p. 59). La primera parte de este lema debe entenderse en un sentido regulativo, normativo y teleológico: la acción del hombre en el mundo debe estar encaminada por el propósito de la transformación de lo real hacia su concordancia con los principios de la racionalidad. Si en la Ciencia de la Lógica sí se consigue, en la Idea absoluta, el fin de una auto-transparencia sin restos de la realidad, en cambio la acción humana en el mundo debe lidiar con la materialidad, con el tiempo y el espacio, con esa testarudez de la Naturaleza que, como si fuera el mítico Proteo, no se deja amoldar a las exigencias del concepto ${ }^{20}$. Curiosamente la denominación de "Proteo de mil formas" aparece en otro

verzweifelt suchen mußte, nach einem Vorbild nähmilch, das seit Winckelmanns Hauptwerk (1755) bis zu dem Tod von Hegel und von Wilhelm von Humboldt (1831), das Wunschbild der Gelehrsamkeit Deuschlands blieb: das Griechenlandbild".

${ }^{19}$ Cfr. Taminiaux (1967, p. VII): "Deux penseurs que cite Nietzsche sont au centre de notre propos : Kant et Hegel. Le premier ne professe aucune espèce de nostalgie de la Grèce. L'œuvre du second, encore qu'elle prenne appui sur Kant, prétend dépasser celui-ci en même temps qu'elle se débarrasse de la nostalgie de la Grèce qui avait imprégné sa lente maturation".

${ }^{20}$ Cfr. Duque (2000, p. 109): “Aquí, en la filosofía de la naturaleza (y también, después, en la del Espíritu), el curso es inverso al de la Lógica: en lugar de irse condensando lógicamente la realidad según se «asciende» por ella, hasta lograr el cierre perfecto de la «objetividad», el empuje de la naturaleza si va haciendo mayor (va retomando pues la Naturaleza salvaje) cuanto más compleja es la realidad considerada. Si «Naturaleza» significa inmediatez, caos e impotencia ante el concepto, entonces la Naturaleza desborda con mucho el marco de la filosofía a ella destinada, e irrumpirá con cada vez mayor vigor, como veremos, en la esfera del espíritu. El retorno a la Idea va acompañado de una paralela pujanza de lo natural". 
poema de Hegel, de 1798, dedicado justamente a la naturaleza ${ }^{21}$. La constante irrupción de lo material, de lo corporal, de lo físico, cada vez en niveles superiores del sistema, es la que impide la perfecta conciliación de realidad y racionalidad, y posterga esta unión ad infinitum, constituyendo por lo tanto el acicate de una incesante actividad de la humanidad por controlar lo incontrolable.

Es interesante notar que el joven Hegel confiará a otra poesía de 1798, dedicada a su perro, el mismo problema de la relación entre el concepto y la naturaleza. Este poema comienza con un verso — “Trazando grandes círculos [el perro] se escapa por el llano, nosotros su punto de retorno" (Hegel, 2014b, p. 486) - que sitúa desde el comienzo una posición central de la comunidad humana, espiritual, frente al carácter huidizo, marginal, incontrolable, de la naturaleza. La lucha entre razón e instinto se escenifica, en los versos centrales del poema, como una lucha violenta entre el perro y su amo:

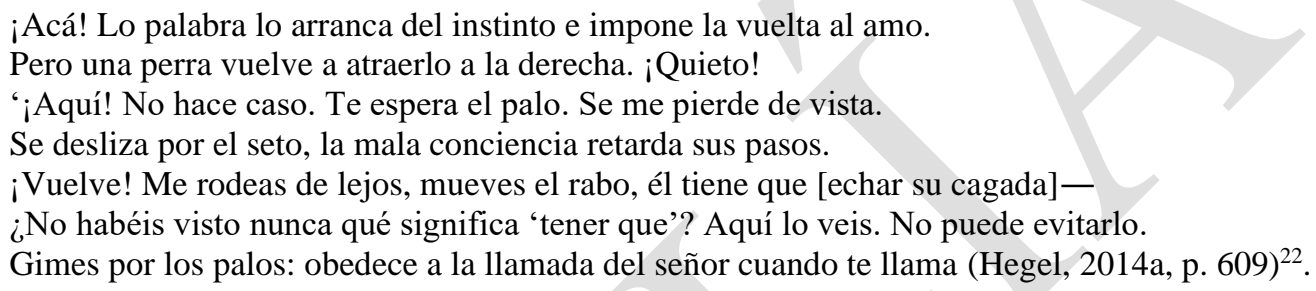

La violencia del palo y la violencia del concepto (de la palabra imperativa, pero también de la ironía que lleva a Hegel a llamar "él” a un perro, cuando esta expresión en alemán esta era una anticuada fórmula de cortesía ${ }^{23}$ ) son aquí la manifestación de una unificación inmediata -y por ello insuficiente - entre razón e instinto a través de la ley moral. Contra esta inmediatez (tildada por Hegel con escasa precisión conceptual "precipitación") de la conjunción entre naturaleza y concepto, entre ser y deber ser, deben entenderse justamente algunos de los versos del poema (sin fechar y sin titular) escrito por Hegel en 1800, y que comienza con el verso "¡La primavera amenaza! Urge a la vida ahí fuera":

\footnotetext{
Que el espíritu se una, pues, con la natura, pero sin precipitación ni antes de iniciarse, pues a quienes ya se tienen por unidos los separa aún, alta sacerdotisa, tu rigor (Hegel, 2014a, p. 611) ${ }^{24}$.
}

De una manera quizás más refinada poéticamente, pero coincidente en lo fundamental con los anteriores dos poemas, lo que impide en Eleusis la unificación entre lo deseable y lo real no es ni el palo ni la precipitación, sino el suspiro, correlato físico del anhelo, y por lo tanto manifestación perceptible de lo natural que hay en el hombre, de su parte animal, psicológica, que nunca se deja acallar por el pensamiento. En Eleusis, por tanto, el sueño de una reconciliación inmediata de las contradicciones y fisuras que estructuran nuestro mundo se revela falaz, y es puesto en fuga por algo

\footnotetext{
${ }^{21}$ Cfr. Hegel (2014a, p. 610), traducido en (Hegel, 2014b, p. 486]: "La tristeza embarga a tus amigos, ¡oh Natura! / Tú, Proteo de mil formas".

22 Traducido en (Hegel, 2014b, p. 486).

${ }^{23}$ Así lo destaca Ripalda en la nota 2 de (Hegel, 2014b, p. 486).

24 Traducido en (Hegel, 2014b, p. 488).
} 
tan frágil, pero a la vez tan invencible en cuanto manifestación de una irreducible singularidad, materialidad y mortalidad, como un suspiro. El sueño que pretendía una fuga hacia el amigo, a través de la eliminación de los obstáculos físicos que lo separan de Hegel, huye a su vez, se desvanece por imposible. Si negar lo físico, lo natural que hay en el hombre nos hunde por un momento en el Todo de la Naturaleza, y por lo tanto nos niega como individuos, en cambio el suspiro recuerda inmediatamente al yo que el hombre es "un animal, es decir, esa cosa misma que niega [...]. Negar la Naturaleza es negar el animal que sirve de soporte de la Negatividad del Hombre" (Bataille, 2005, p. 18). Y eso es inaceptable para Hegel, para quien si es cierto que sólo la muerte de la naturaleza es la vida del espíritu ${ }^{25}$, también lo es que para efectuar ese asesinato ${ }^{26}$ es necesario digerir, como en una lenta masticación, todos los residuos que deja esparcidos la segunda parte de la Enciclopedia; pero, como se ha dicho, es muy probable que, a pesar de su titánico esfuerzo sintético, el método dialéctico desplegado por Hegel no consiga llevar a término esa asunción sin restos, sino que la apunta como un ideal regulativo, como un fin final de suyo inalcanzable. La muestra de ello es, al final de la Enciclopedia, ese tercer y último silogismo que deja abierto el polo de la Naturaleza, como un gigantesco punto de interrogación como conclusión de todo el sistema hegeliano.

Pero volvamos al poema: una tentación más fuerte que la de la supresión de la distancia física entre él y el amigo invade al ¿poeta?-filósofo, una tentación a la que tantos han sucumbido, y muchos por cierto en esas mismas fechas. Igual que Leopardi, para quien "il naufragar m'è dolce in questo mare" (Leopardi, 2001, p. 280), el mar de la infinitud, Hegel se pierde en el dulce océano del cielo estrellado, de la inmensidad que nos hace olvidarnos de nosotros mismos; este náufrago a la deriva se deja atraer por el terrible peligro de las sirenas de la intuición.

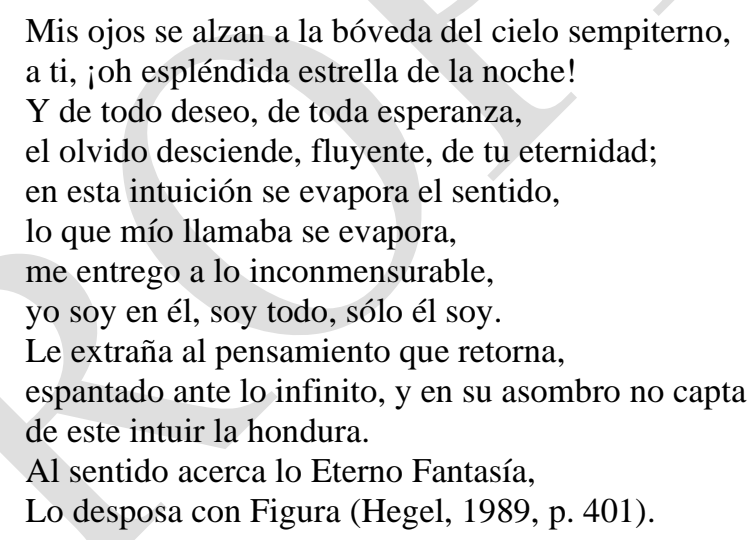

La tercera fuga que nos habla desde Eleusis es la pérdida del Sí-mismo en los abismos de la intuición. Estos últimos versos son los que Hegel tachó después de la redacción, quizás arrepentido de este flirteo con esa "noche en la que todas las vacas son negras" (Hegel, 1980, p. 17). Sin embargo,

\footnotetext{
${ }^{25}$ Cfr. Hegel (1980, p. 28): "Die kraftlose Schönheit haßt den Verstand, weil er ihr dies zumutet, was sie nicht vermag. Aber nicht das Leben, das sich vor dem Tode scheut und von der Verwüstung rein bewahrt, sondern das ihn erträgt und in ihm sich erhält, ist das Leben des Geistes".

${ }^{26}$ Cfr. Duque (2000, p. 112): "La naturaleza no se mata tan fácilmente. Ella sigue ascendiendo, obstinadamente, a través de los vericuetos, de las vueltas y revueltas del espíritu (lo natural es esa revuelta)"
} 
este romance con algunas tesis románticas no se había tratado de una aventura inconfesable de un día, de una "scappatella", equivalente italiano de "una cana al aire" que literalmente significa "pequeña huida". No estamos aquí ante una momentánea traición a sí mismo, motivada quizá por la exaltación y el páthos de la escritura: “a [...] la superioridad de la intuición (intelectual) sobre el concepto (del entendimiento) seguirá fiel Hegel hasta al menos 1802 (siendo el Sistema de la eticidad el decisivo punto de inflexión)" (Duque, 1998, p. 355). Por lo tanto, estos versos tachados constituyen un arrepentimiento, un pentimento en su sentido técnico artístico, no de una sola obra, sino de toda una etapa de juventud en la que Hegel no era todavía Hegel. Esta huida hacia un claro panteísmo en el que el Hen kai pan es llevado hasta sus límites más peligrosos, los de la disolución del individuo en la totalidad inconsciente de la realidad, de todos modos, no se encuentra reconducida a su cauce sólo mediante la posterior tachadura de Hegel. De hecho, puede decirse que el entero poema constituye ya una lucha encarnizada contra esos versos, un asedio a la tentación representada por esa pérdida de sí en el todo. Lejos de quejarse, como hará Schelling, por la vuelta que, necesariamente, tras la intuición intelectual de lo Sagrado nos devuelve a los "horrores del mundo objetivo" (Schelling, 1886, p. 337), Hegel se esfuerza por mostrar cómo esos horrores, si se comprende su desarrollo racional interno y su íntima necesidad, son ya de por sí lo Sagrado. Contrario a la idea de toda trascendencia, incluso en su presunta fase panteísta Hegel sigue apostando por la realidad concreta, y por su transformación a través de la acción política.

Esta postura queda clara por la que podemos denominar como "la cuarta huida" del poema Eleusis, que muestra una clara influencia hölderliniana en cuanto a la elección de las palabras, aunque no del mensaje; tras alabar el entusiasmo que "sentiría", "percibiría", "interpretaría" si pudiera escuchar "lo himnos del convivio divino", los ritos iniciáticos de los misterios eleusinos, Hegel sentencia con dureza:

Pero tus salas han enmudecido, ;oh Diosa!

Huido está el círculo divino, de vuelta en el Olimpo,

Dejando atrás altares profanados.

¡Del degradado sepulcro de los hombres, huido

de la inocencia del Genio, que aquí los encantaba! (Hegel, 1989, p. 401).

La huida de los dioses, el fin de los ritos eleusinos, la imposibilidad de esa relación inefable con Ceres es descrita con aparente nostalgia, y con una correlativa crítica —esa sí, sincera, e inspirada probablemente por el poema Los dioses de Grecia de Schiller, de 1788, como sostiene Highet (1996, p. 134)-, hacia los fríos saberes como la arqueología, que pretenden hoy en día sin éxito reconstruir la esencia de esas celebraciones, de esa religión mistérica. Pero esta desaparición no deja al hombre ante el vacío del nihilismo, o a la busca de nuevos ídolos, materiales o ideológicos, a los que deificar. Hegel tiene ya claro que Dios vive en las acciones de los hombres, en el bello vínculo de la comunidad edificada sobre esa "fe leal" de la que hablan los versos finales:

Avaros tus hijos no exhibieron, Diosa, tu honor por calles ni mercado, lo guardaron en el interno santuario de su pecho; 


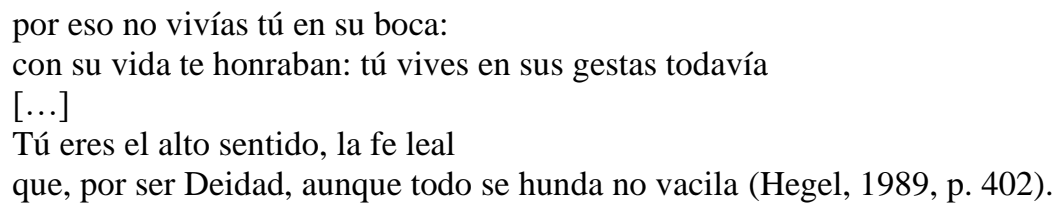

En una especie de Pentecostés pagana, el espíritu de Ceres, una vez que ésta ha huido, se hace comunidad, se hace "alianza" entre un yo y un tú, entre dos amigos que están deseando reencontrarse ${ }^{27}$. Por ello, ante todo, Eleusis es un escrito político, o mejor dicho un escrito "polémico, de combate" (Duque, 1998, p. 356). Frente a la tentación de la supresión de sí mismo en un todo informe, esa huida hacia a la intuición de la que hablábamos antes, Hegel propone la in-formación de mundo y de comunidad, dado que esa acción, esa gesta colectiva es la única divinidad que cabe construir. Impregnado de una melosa nostalgia romántica cuando nos enfrentamos a él en una primera lectura, Eleusis constituye en cambio un poderoso antídoto contra toda nostalgia acrítica que pretenda volver a un pasado soñado e irrecuperable. Aparentemente constelado de fugas hacia atrás y hacia el fondo, este poema, como toda la filosofía de Hegel, huye de esas fugas, y pro-pone una marcha organizada, constructiva, colectiva hacia delante, para hacer comunidad ${ }^{28}$.

\section{Referencias bibliográficas}

BAtAILle, G. (2005). Escritos sobre Hegel. Madrid: Arena.

BERTAUX, P. (1992). Hölderlin y la Revolución Francesa. Barcelona: Ediciones del Serbal.

D’HondT, J. (1976). Hegel Secreto. Buenos Aires: Corregidor.

D’HondT, J. (2002). Hegel. Barcelona: Tusquets.

DuQUE, F. (1996a). 'Schöneres kann nicht sein und werden'. Das Griechenlandbild bei Hegel und Hölderlin. En Ch. JAMmE (Ed.), Kunst und Geschichte im Zeitalters Hegel (pp. 27-54). Hamburgo: Felix Meiner.

DuQue, F. (1996b). El corazón del pueblo. La "religión” del Hegel de Berna. En O. Market y J. RIVERA DE Rosales (Coords.), El inicio del idealismo alemán (pp. 237-262). Madrid: U.C.M. / U.N.E.D.

DuQUe, F. (1998). Historia de la filosofía moderna. La era de la crítica, Akal: Madrid.

DuQue, F. (2000). Pensando en libertad las razones de Hegel. En M. Álvarez Gómez y M. C. PAREDES MARTín (Eds.), Razón, Libertad y Estado en Hegel (pp. 91-118). Salamanca: Ediciones Universidad de Salamanca.

HARRIS, H. S. (1972). Hegel's Development. Vol. I. Oxford: Clarendon.

\footnotetext{
${ }^{27}$ Cfr. Harris (1972, pp. 247-248): "The fundamental conviction expressed in the poem is that the particular forms to which the eternal truth was 'married' in Greek religion are not necessary for the reopening of the temple gates. Both the splendour and the moral substance (Ernst) of that ideal belong to human life everywhere where men cleave firmly to the spirit of the 'old covenant' between Hegel and Hölderlin'.

28 "To be modern is to realize that this critical stance of making a home in our partially alienated world is our own modern destiny. To be modern, that is, to be Hegelian" (Pinkard, 2003, p. 216).
} 
Hegel, G. W. F (1980). Phänomenologie des Geistes. En G. W. F. HeGEL, Gesammelte Werke, Band 9. Hamburgo: Felix Meiner.

Hegel, G. W. F. (1989). Frühe Schriften I. En G. W. F. Hegel, Gesammelte Werke, Band 1. Hamburgo: Felix Meiner.

Hegel, G. W. F., (2005). Principios de Filosofía del Derecho. Barcelona: Edhasa.

Hegel, G. W. F. (2014a). Frühe Schriften II. En G. W. F. HegEL, Gesammelte Werke, Band 2. Hamburgo: Felix Meiner.

HEGEL, G. W. F. (2014b). El joven Hegel. Ensayos y esbozos. Madrid: FCE.

HeIDEGGER, M. (2001), Hitos. Madrid: Alianza.

HigheT, G. (1996). La tradición clásica, Vol. II. México: FCE.

HoffMeister, J. (1952). Briefe von und an Hegel, Band I. Hamburgo: Felix Meiner.

HöLDERLIN, F. (1982). Hiperión o el eremita en Grecia. Madrid: Ediciones Hiperión.

Kelly, G. A. (1978). Hegel's Retreat from Eleusis. Studies in Political Thought. Princeton: Princeton University Press.

LEOPARDI, G., (2001). Tutte le poesie e tutte le prose. Roma: Newton Compton.

MANZONI, A. (2006). Opere complete. Milán: Mondadori.

MARX, K. (1973). La Sagrada Familia. Buenos Aires: Claridad.

PINKARD, T. (2003) Agency, Finitude and Idealism: What does it mean to be a Hegelian today? En W.

WelsCh y K. VIEWEG (Eds.), Das Interesse des Denkens. Hegel aus heutiger Sicht (pp. 205216). Munich: W. Fink Verlag.

Pozzo, R. (1989) Hegel: 'Introductio in philosophiam'. Dagli studi ginnasiali alla prima Lógica.

Florencia: La Nuova Italia.

RiPALDA, J. M. (1978). La nación dividida. México: FCE.

Rocco Lozano, V. (2011). La vieja Roma en el Hoven Hegel. Madrid: Maia.

Rocco Lozano, V. (2019). Roma abscondita: the hidden Presence of Latin Poetry in the

Phenomenology of Spirit. En F. IAnNeldi, F. Vercellone y K. VieweG (Eds.), Hegel und Italien, Italien und Hegel. Geistige Synergien von gestern und heute (pp. 133-152). Milán-Udine: Mimesis.

Rosenkranz, K., (1844). G. W. F. Hegel's Leben, Berlin: Duncker und Humblot.

SCHElling, F. W. J. (1856). Philosophische Briefe über Dogmatismus und Kriticismus. En F. W. J.

SCHELLING, Brief Samtliche Werke I. Stuttgart/Augsburg: Cotta.

SHAKESPEARE, W. (2006). Macbeth, Otelo y Julio César. Madrid: Edaf.

TAMINIAUX, (1967). La nostalgie de la Grèce á l'aube de l'idéalisme allemand. La Haya: M. Nijhoff. 